\title{
Influence of Alkali Treatment and Maleated Polypropylene (MAPP) Compatibilizer on the Dry-Sliding Wear and Frictional Behavior of Borassus Fruit Fine Fiber (BFF)/Polypropylene (PP) Polymer Composites for Various Engineering Applications
}

\author{
Sumit Nijjar $\mathbb{D}^{1},{ }^{1}$ P. Sudhakara $\mathbb{D}^{2},{ }^{2}$ Shubham Sharma $\mathbb{D}^{2},{ }^{2}$ Sanjeev Saini, ${ }^{3}$ \\ Aklilu Teklemariam $\mathbb{D}^{4}{ }^{4}$ V. Mariselvam, ${ }^{5}$ Satheesh Kumar Sampath, ${ }^{6}$ and J. I. Song ${ }^{7}$ \\ ${ }^{1}$ IKG Punjab Technical University, Jalandhar-Kapurthala Highway, VPO Ibban, Kapurthala 144603, India \\ ${ }^{2}$ CSIR-Central Leather Research Institute, RCED, Jalandhar 144021, India \\ ${ }^{3} D A V$ Institute of Engg, Management and Tech, Kabir Nagar, Jalandhar, India \\ ${ }^{4}$ Department of Mechanical Engineering, Faculty of Manufacturing, Institute of Technology, Hawassa University, \\ Awasa, Ethiopia \\ ${ }^{5}$ Dept of Electronics and Communication Engineering, M. Kumarasamy College of Engineering, Karur 639113, India \\ ${ }^{6}$ Electrical and Electronics Engineering, University of Technology and Applied Sciences, Muscat, Oman \\ ${ }^{7}$ Department of Mechanical Engineering, Changwon National University, Changwon 641773, Republic of Korea
}

Correspondence should be addressed to Sumit Nijjar; sumitnijjar.davu@gmail.com, P. Sudhakara; sudhakarp@clri.res.in, and Aklilu Teklemariam; akliluteklemariam@hu.edu.et

Received 16 October 2021; Revised 18 November 2021; Accepted 20 November 2021; Published 24 December 2021

Academic Editor: V. Vijayan

Copyright (C) 2021 Sumit Nijjar et al. This is an open access article distributed under the Creative Commons Attribution License, which permits unrestricted use, distribution, and reproduction in any medium, provided the original work is properly cited.

Tribological properties of the novel Borassus fruit fine fiber- (BFF-) reinforced polypropylene (PP) composites with respect to fiber matrix surface modifications have been described. Composites were fabricated by an injection molding process using Borassus fruit fine fiber (BFF) of $5 \mathrm{wt} . \%$ as reinforcement and polypropylene (PP) as a matrix component. Fibers were treated with alkali (T) to remove the residual lignin (if present) and to enhance the interfacial adhesion between the fiber/matrix interface. Alkali treatment reveals additional reactive functional groups here on the surface of the Borassus fiber, allowing effective interaction bonding with the polypropylene matrix. Borassus fibers are primarily treated with an alkali solution to extract weaker unstructured amorphous constituents so that the fibers retain crystallized components, thereby strengthening the fiber's strength. A $5 \mathrm{wt} . \%$ of maleated polypropylene (MAPP) was used as a compatibilizer to improve the interfacial adhesion between fiber and the polymer matrix. The wear and frictional behavior of BFF/PP composites with respect to the modifications were evaluated by steel counterface utilizing pin-on-disc test contraption under dry-sliding conditions. The sliding velocity, applied load, and sliding distance were maintained as $2.198 \mathrm{~m} / \mathrm{s}, 9.81-29.43 \mathrm{~N}$, and $4000 \mathrm{~m}$, respectively. The results demonstrate that the reinforcement of $\mathrm{BFF}$ to polypropylene matrix and the modifications improved the wear properties of the neat polymer matrix. Findings concluded that the abrasive wear resistance of $\mathrm{T}+\mathrm{PP}+\mathrm{MAPP}$ composite showed better interfacial adhesion and bonding, thus resulting in better tribological performance as compared to the other three compositions under different loading conditions. The effective substantial improvement of the coefficient of friction has been observed in alkali-treated fiber and polypropylene matrix with MAPP compatibilizer ( $\mathrm{T}+\mathrm{PP}+\mathrm{MAPP})$ composites due to the presence of MAPP compatibilizer and alkali-treated fibers. The frictional coefficient of T + PP + MAPP possesses better interfacial bonding strength upon $\mathrm{NaOH}$ treatment, and coupling agent, which results in enhancement of effective contact surface area and good surface friction characteristics, has been observed under different loading conditions. The fracture mechanism of worn-out portions of BFF/PP composites was studied using highresolution scanning electron microscopy to analyze various imperfections like debonding, splits, fiber cracks, and wreckage or fragments formation. 


\section{Introduction}

Polymer matrix composites (PMC) have shown a huge possibility due to their lower cost, good lubricating properties, and lower weight to strength ratio [1]. Many researchers have reported that the tribobehavior of the composite materials was enhanced by adding natural fiber in the polymer matrix; however, this behavior was dependent on the fiber orientation, length, volume fraction, fiber size, and test conditions like load, speed, and temperature [2]. The research work and the applications of natural fiber polymer composite (NFPC) material are gradually increasing, mainly due to environmental concerns. The dimensional shape and friction behavior of NFPC can improve by adding fillers. The change in the friction behavior of NFPC by adding fillers has shown much importance and attracted research interests. Most of all mechanical elements which are in motion are experiencing friction, which leads to the mass loss of the materials. Many researchers have worked on the natural fiber-reinforced polymer composites to identify the friction behavior of the materials. The relatedness of researchers is determined based on their number of coauthored publications as exhibited in Figure 1.

Hasmi et al. [3], while working on cotton fiber polyester resin with graphite filler composites with varying load and sliding distance, observed that the coefficient of friction (COF) of the material was higher for the graphite filled material compared to the unfilled one. The authors studied the sliding wear performance of cotton fiber-reinforced polyester composites for various load applications by using different graphite weight proportions. The specific wear rate of composites was diminished upon an increase in graphite content with the incorporation of cotton fibers. Yousif and El-Tayeb [4] observed the friction behavior of untreated and treated oil palm polyester composites and revealed that, for treated fiber, COF of the material decreased with increasing load. Yousif et al. [5] worked on coir fiber-reinforced polyester composites and analyzed the COF of material with varying load and sliding distance. They revealed that the $\mathrm{COF}$ of the material increased with the increasing load condition. Nirmal [6] worked on the treated betel fiberreinforced polyester composites with varying load and sliding distance and proved that the COF of the material decreased with the increasing load. Narish et al. [7] have observed the COF of treated kenaf fiber-reinforced polyurethane with varying load, sliding distance, and fiber orientation. The study came to the conclusion that COF of the material decreased with the increasing load, and also fiber orientation has a significant effect on the friction behavior of the material. Bajpai et al. [8] worked on the sisal fiberreinforced polymer composites and revealed that COF of the material decreases with the load. Shalwan et al. [9] and Ibrahem et al. [10] worked on plant-based natural fiber with the polymer matrix composites with the graphite fillers. Both the studies came to the same conclusion that, with increased graphite filler, the COF of the material was reduced. Dwivedi et al. [11] again reported that, after investigating the tribological performance of Wood Flour- (WF-) reinforced epoxy composites, the addition of WF content enhanced the load-bearing capability and simultaneously reduced its resistance to sliding wear. El-Tayeb [12] compared the tribological performances of sugar cane fiber-reinforced polyester composites and glass fiber-reinforced polyester composites and recommended that the sugarcane fiber as a suitable candidate to reinforce with polyester as it has possessed a greater degree of wear resistance. Witold Brostow et al. [13] have discussed the significance and consequence of tribology of Polymer-Based Materials (PBM). Conventional tribology was made initially for metals that were not suitable for PBM, based on two reasons. First, PBMs are viscoelastic and their properties rely on time, whereas metals and ceramics are not so. Secondly, swelling of PBMs occurs due to the more absorbing capability of external lubricants compared to any class of metals. Moreover, the authors have elaborated the techniques for improving the resistance of PBMs to wear and scratch. Growing involvement in PBMs and their applications in the composite industry as an effective standby for metals and other materials depend on the capability to develop and alter their structures over a broad range. This aids property enhancement as well as alteration of tribological properties. Additional growth in evaluation and enhancements of the tribological properties of polymers and PBMs, that is, their composites and formulations, can be achieved not only by identifying the connection between the friction factors and the wear mechanisms but also by modifying the surface structures at micro- and nanolevels.

Punyapriya et al. [14] focused on evaluating abrasive wear performance of Bagasse Fiber-Reinforced (BFR) epoxy composites with the parallel, antiparallel, and normal direction of fiber arrangement. The authors have further concluded that the rate of abrasive wear of BFR epoxy composite mainly depends upon load and abrasive grit size. The fiber arrangement in the composites has an appreciable effect on wear rate. The results have confirmed that fibers that have normal orientation have a minimum wear rate compared to other parallel and antiparallel arrangements of fibers. Aldousiri et al. [15] reviewed the tribological performance of polymeric materials with regard to man-made fibers along with numerous points which managed the friction and wear properties of such materials like fibers, additives, environment of tribology, interfacial adhesion, composite geometry, and operating parameters. The result showed the potential of substituting the traditional reinforcing fibers with the biodegradable natural fibers. Kamal Kumar et al. [16] developed natural fiber Ipomoea carneareinforced epoxy composites with various weight fractions of $10,20,30$, and $40 \%$. The authors also investigated the wear performance for different loading conditions of $5,7.5,10$, and $15 \mathrm{~N}$ at a variable speed. Abrasive wear loss was diminished by the inclusion of Ipomoea carnea and produced optimum value for 30 weight percent of fiber content. With the increased velocity, the abrasive wear also increased, and with the addition of sliding distance, the rate of wear steadily 


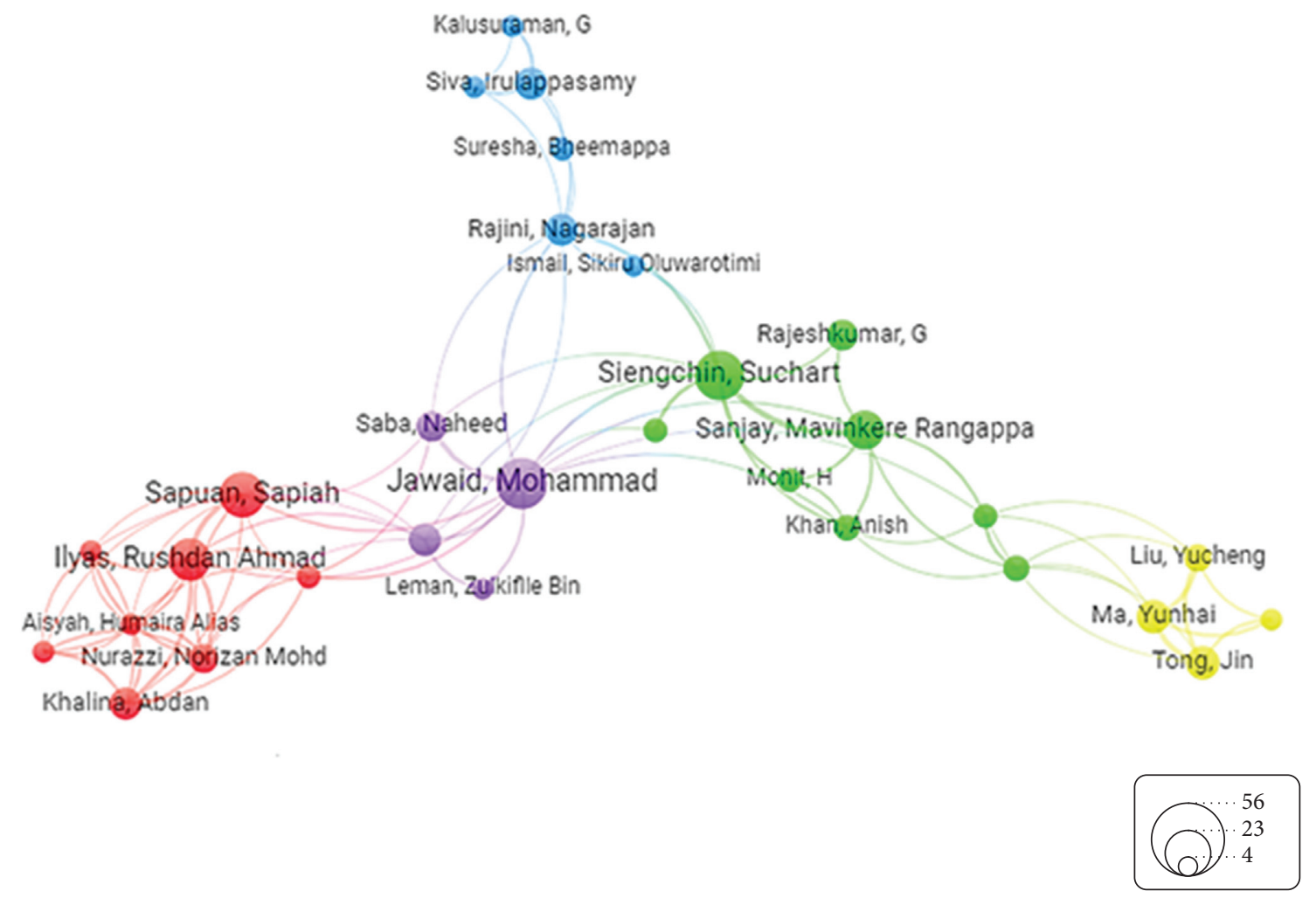

FIGURE 1: Coauthorship analysis in accordance with the influence of surface modifications on natural fiber/polymeric composites (where no. of researchers $=30$; coauthorship links $=85$; and no. of clusters $=5$ ).

reduced. Yusuf Sahin [17] described that polymer composites are developing an eligible substitute to metal and alloys in various latest engineering applications. On account of their combined greater specific strength and specific modulus, polymers and polymer-based composites justify many applications in automotive components like cams, gears, clutches, and brakes and also in other diverse engineering applications such as chute liners, mining, conveyor aids, and other related areas, where wear behavior in the nonlubricated situation is a vital factor for the selection of material. Aranganathan et al. [18] optimized the amount of aramid fiber/pulp required to obtain the best performance frictional material. In total, six frictional materials constituting 0 to $10 \%$ of the weight content of aramid fiber/pulp are prepared and characterized by their physical, chemical, mechanical, and tribological performance. The friction material loaded with $10 \%$ of the weight of aramid fiber shows the best overall performance, while the composite without fibers exhibits the worst performance. Worn surfaces of tested composites are characterized by SEM [19-25]. The literature shows many studies on the wear and friction behavior of NFPC, but hardly any study has been found on Borassus fruit natural fiber with the polypropylene matrix $[26,27]$. The frictional process will lead to material loss, so in this work, the focus is given to study the effect of percent wt. content of BFF and effect of alkali treatment and compatibilizer on the frictional performance of the BFF/PP composites. In the present work, an evaluation and estimation of adhesive wear, frictional behavior along with the influence of alkali treatment ( $\mathrm{NaOH}$ treatment), and use of compatibilizer (MAPP) on the Borassus fruit fine fiberreinforced polypropylene composite material are being emphasized upon as shown in Figure 2, scientometricmapping visualization-based characteristic analysis.

\section{Materials and Methods}

Borassus fruit fiber (BFF) (Figure 3), as stated elsewhere, was obtained from dry seasoned ripene fruit and was used as reinforcing constituents. The coupling agent, poly (propylene)-graft-maleic anhydride (MAPP) (Aldrich) and sodium hydroxide $(\mathrm{NaOH})$ (Dae-Jung Synthetic substances), was purchased from Honam Petrochemical Company, South Korea, and utilized as provided [28, 29].

2.1. Extraction of Fibers from Borassus Fruits. The extraction of fibers from Borassus fruits has been mentioned elsewhere, as discussed in the following $[28,29]$. The fibers of Borassus flabellifer have been obtained using dry ripening fruits. The fruits were soaked in water for two weeks first before the black peel skin shell covering was removed. Below, two different kinds of filament strands have been observed: long coarse fibers and shorter fine fibers. The coarser filament strands were prevalent within fruit nuts nearly various edges; however, the fine fibers were adherent to the fruit shell. Both varieties of fibers were carefully cleaned with water from the tap, subsequently accompanied by distilled water, and then left to dry in sunlight for the whole week. The fibers were then placed in a hot furnace for $24 \mathrm{hrs}$ at $105-110^{\circ} \mathrm{C}$ to 


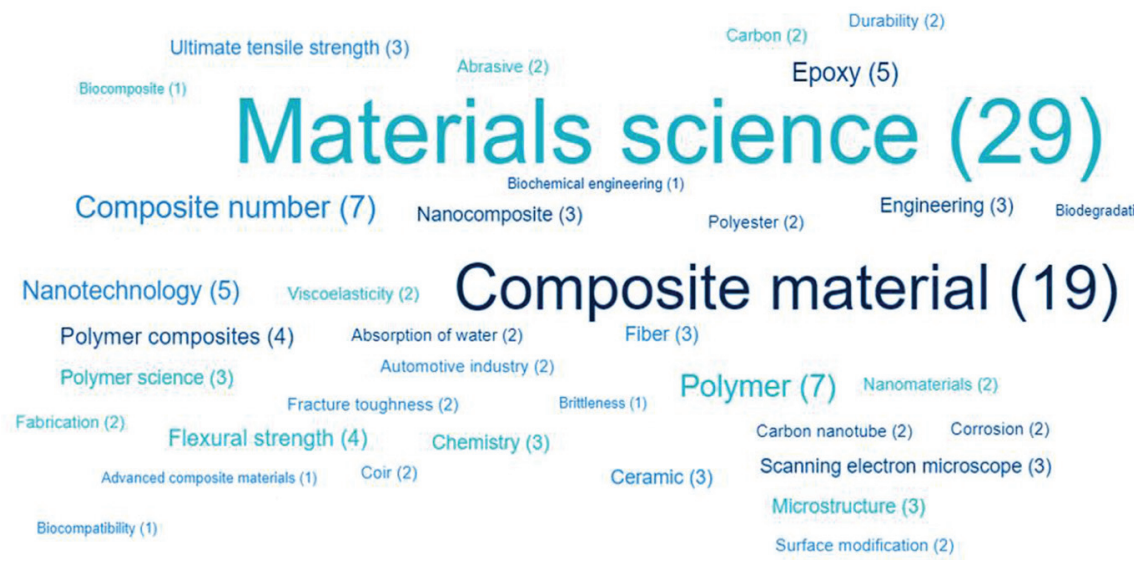

FIGURE 2: Unigraphics visualization showing the keywords facet on the influence of surface modifications and compatibilizers on the natural fiber-reinforced polymer composites.

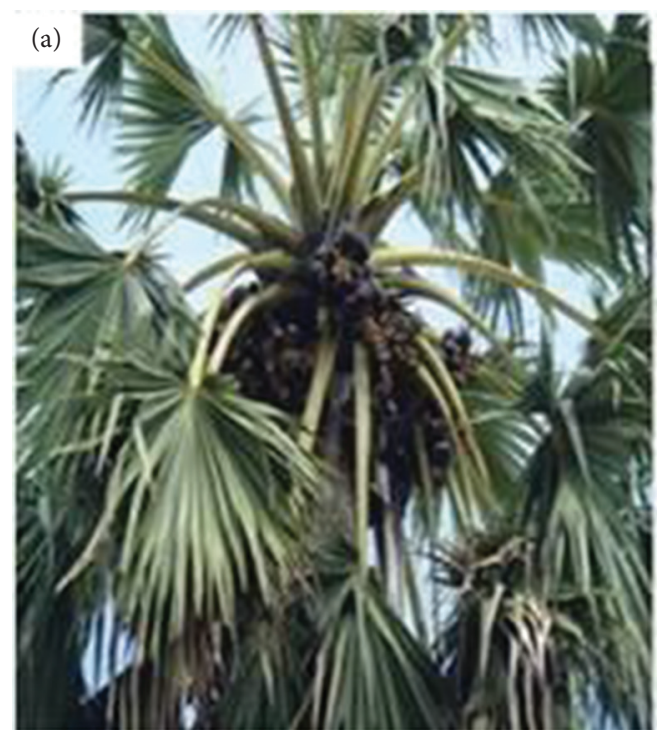

(c)

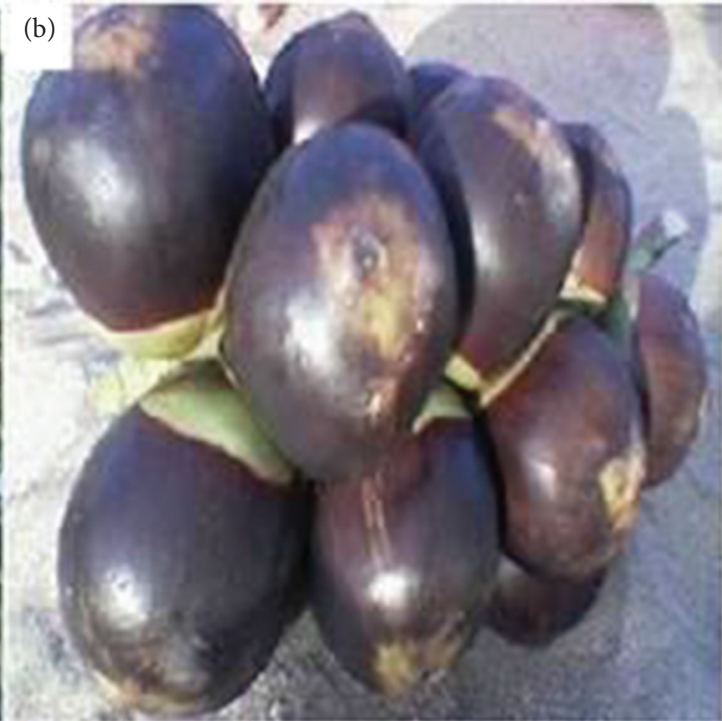

(d)

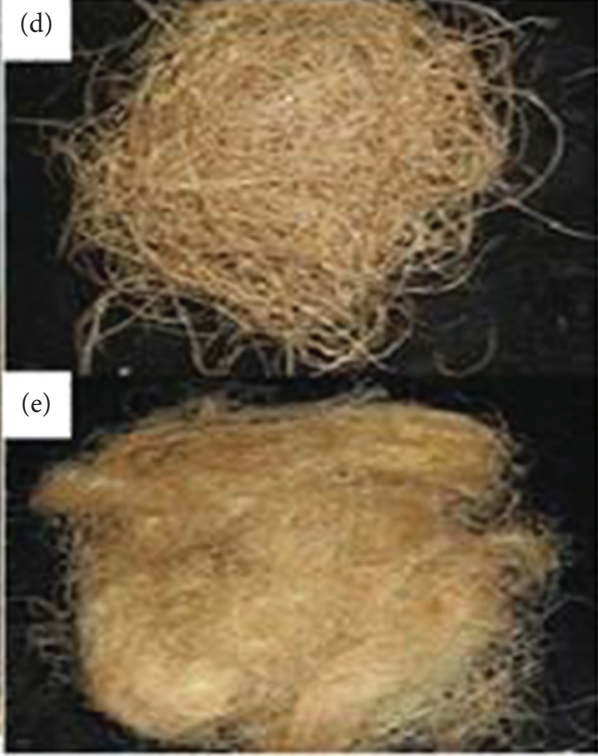

Figure 3: (a) Borassus tree, (b) natural products, (c) dried organic products, (d) Borassus natural product coarse filaments, and (e) fine strands $[28,29]$. 
extract the moisture content. At an ambient temp., a fraction of Borassus fibers were processed with a 5-percent of aqueous $\mathrm{NaOH}$ solutions with a liquor proportion of $30: 1$, and also the filament strands were then dipped throughout in the alkali solution for thirty minutes to extract the hemicellulose as well as other fatty viscous grease/oil-based elements. The fibers were then continuously thoroughly rinsed and processed with mild acetic acid. Ultimately, the fiber strands were properly cleaned prior to getting dried in such a hot furnace for 24 hours.

2.2. Composites Fabrication. To extract dirty filth, muddy dust, and other moisture-soluble contaminants, BFF fibers were initially cleaned with distilled water and soaked for 24 hrs. Drained fabrics were processed at ambient temperature with 4 percent $\mathrm{NaOH}$ for $5 \mathrm{~h}$, keeping 1:20 liquid proportion. The fabrics were extracted and cleaned with distilled water till the fibers exhibited minimal remnant $\mathrm{NaOH}$ (neutral $\mathrm{pH}$ ) and cured for $24 \mathrm{hrs}$ in a sealed vacuum oven at $70^{\circ} \mathrm{C}$. The treated and untreated dry alkali fibers were chopped within a span of $5-10 \mathrm{~mm}$ and preserved in a ziplock polybag. Figure 4 illustrates the proposed research methodology to carry out the effect of alkali treatment and compatibilizer on the sliding wear analysis and frictional force of PP/BFF composite.

In a corotating twin-screw extruder (PRISM, TSE 16TC, Thermo Electron Corporation), the dry short-staple fibers, PP and MAPP (for newly developed polymers), were liquefy compounded. The cylinder barrel-portion temperature from the dispenser to the tool was $180-190^{\circ} \mathrm{C}$, and the screw extruder speed was $120 \mathrm{rpm}$, respectively. The extrudate was eventually pelletized using a grinder fitted with a collection of knives and various grids. Such granules were dried for minimum $24 \mathrm{hrs}$ in an oven at $80^{\circ} \mathrm{C}$ and injection molded (WOOJIN, SELXR CO. LTD) into standardized samples to evaluate the tribological properties. The temperature and pressure of the injection molding were $200^{\circ} \mathrm{C}$ and $60 \mathrm{MPa}$. The fibers appeared to get tightly packed due to the widespread extraction of hemicellulose through mercerization and the development of novel hydrogen-intermolecular bonding among the polysaccharide fiber-like strand chains, while the small fibers were reorganized quite compactly, thereby leading to closely packed fiber density [28, 29] as indicated in Figure 5. SEM micrographs as exhibited in Figures 6(a) and 6(b) signify that the fabricated BFF/PP composites showed better interfacial bonding among the PP matrix and BFF fruit fibers. No such gaps and fiber pullout imperfections were observed for the fabricated composites and thus instigated better mechanical characteristics. As it is clearly evident from Figure 6(b), in untreated BFF/PP composite, the interfacial adhesion bonding is significantly better as compared to Figure 6(a), that is, alkali-treated BFF/ PP composite.

2.3. Wear Test and Morphological Studies. Tribological properties were measured by using steel counterface utilizing pin-on-disc test tribometer (Ducom India; TR20LE) under dry-sliding conditions as shown in Figure 7. The raw and alkali-treated specimens of $10 \mathrm{~mm}$ diameter and $75 \mathrm{~mm}$ length, which were reinforced with $3 \mathrm{~mm}, 5 \mathrm{~mm}$, and $7 \mathrm{~mm}$ length Borassus fruit fibers, were slid against the stainless steel disc (EN 31, $64 \mathrm{HRC}$ ) of $140 \mathrm{~mm}$ diameter and $8 \mathrm{~mm}$ thickness. The loading range applied was $9.81 \mathrm{~N}$, $19.62 \mathrm{~N}$, and $29.43 \mathrm{~N}$, with a sliding velocity of $2.198 \mathrm{~m} / \mathrm{sec}$. The wear test duration of $15 \mathrm{~min}$ with the corresponding speeds of $300 \mathrm{rpm}-500 \mathrm{rpm}$ for a radial sliding distance of $4000 \mathrm{~m}$ was considered. The stainless steel disc was cleaned every time to remove the debris, remainders, and so on before fixing the next specimen for the wear test. A precise $0.0001 \mathrm{gm}$ balance was used to measure the weight loss of the pins.

The surface micrographs of the worn specimens were observed using JSM-6390 Field Emission-Scanning Electron Microscope (FE-SEM). The specimens were scanned with a high-energy electron beam in a raster fashion. The interaction of the thin electron beam with the atoms of the specimen provided three-dimensional magnified appearances of the surfaces. The specimens were mounted on the aluminum grippers of the microscope using carbon adhesive tabs. The specimens were sputtered with a gold layer prior to the SEM observations.

\section{Results and Discussions}

3.1. Wear Test. The technique for sliding wear analysis was pursued according to ASTM G99-95 standards. The composite samples of the desired size were cut from the formed composite samples. The tests were conducted by selecting load, speed, and sliding distance as the input variables. The BFF fibers were kept in normal to the load condition, and the surface of the composite's specimen was rubbed over the countersurface. The specimen was rubbed on different grade emery paper for proper surface contact before performing each experiment. The wear conduct of polymers reinforced with untreated fibers $(\mathrm{U}+\mathrm{PP})$, alkali-treated fibers/PP $(\mathrm{T}+\mathrm{PP})$, untreated fibers/PP with maleic anhydride $(\mathrm{U}+\mathrm{PP}+\mathrm{MAPP})$, and alkali-treated fibers/PP with MAPP ( $\mathrm{T}+\mathrm{PP}+\mathrm{MAPP})$ is shown in Figures $8(\mathrm{a})-8(\mathrm{~d})$ to $9(\mathrm{a})-9(\mathrm{~d})$. Accordingly, as the weight loss for the loading range was expected to be marginal at $9.81 \mathrm{~N}$, the weight loss was estimated above $19.62 \mathrm{~N}$ loads. The penetration was also lower at this load of $19.62 \mathrm{~N}$ and thus contributed to a lower weight loss during rubbing. It was important to note that, due to the increase in load as well as the change in speeds, the penetration and consequently the weight loss were increased proportionally. The weight loss for the subsequent loads and speeds for the treated FRP was found to be lower than raw FRP. The friction behavior of the materials was noted as a function of load (L), velocity (S), and sliding distance (SD) as operating parameters and studied as a function of different weight concentrations of fillers as material parameters. Table 1 shows the details of BFF/PP composite specimens and sliding test conditions. The wear rate of the specimens was determined utilizing the accompanying relation.

Specific wear rate, $k_{s}=\Delta m / p L F M$, where $m$ is the weight loss (g), $\rho$ is the compactness or density of the sample $\left(\mathrm{g} / \mathrm{cm}^{3}\right), L$ is the sliding distance $(m)$, and $F_{n}$ is the applied normal load $(\mathrm{N})$. 


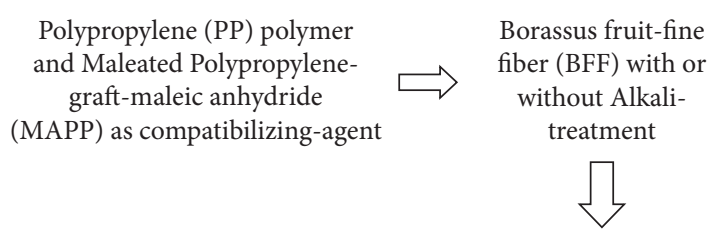

Fabrication of Borassus fruit-fine fiber (BFF) reinforced Polypropylene (PP) composites using Injection moulding with four different compositions

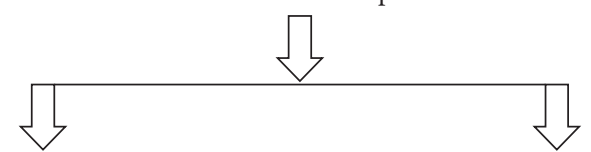

Evaluation of Tribological properties:

(i) Specific wear-rate, and Coefficient of Friction
Examination of Morphological properties:

(i) FE-SEM analysis of worn surfaces

\section{Fabricated composite specimens}

(i) Untreated fibers/Polypropylene (U+PP)

(ii) Alkali-treated-fibers/Polypropylene (T+PP)

(iii) Untreated-fibers/Polypropylene-graftmaleic anhydride (U+PP+MAPP)

(iv) Alkali-treated-fibers/Polypropylene-graftmaleic anhydride $(\mathrm{T}+\mathrm{PP}+\mathrm{MAPP})$

Where, 'T' refers to the Alkali treatment

FIGURE 4: Proposed research methodology.
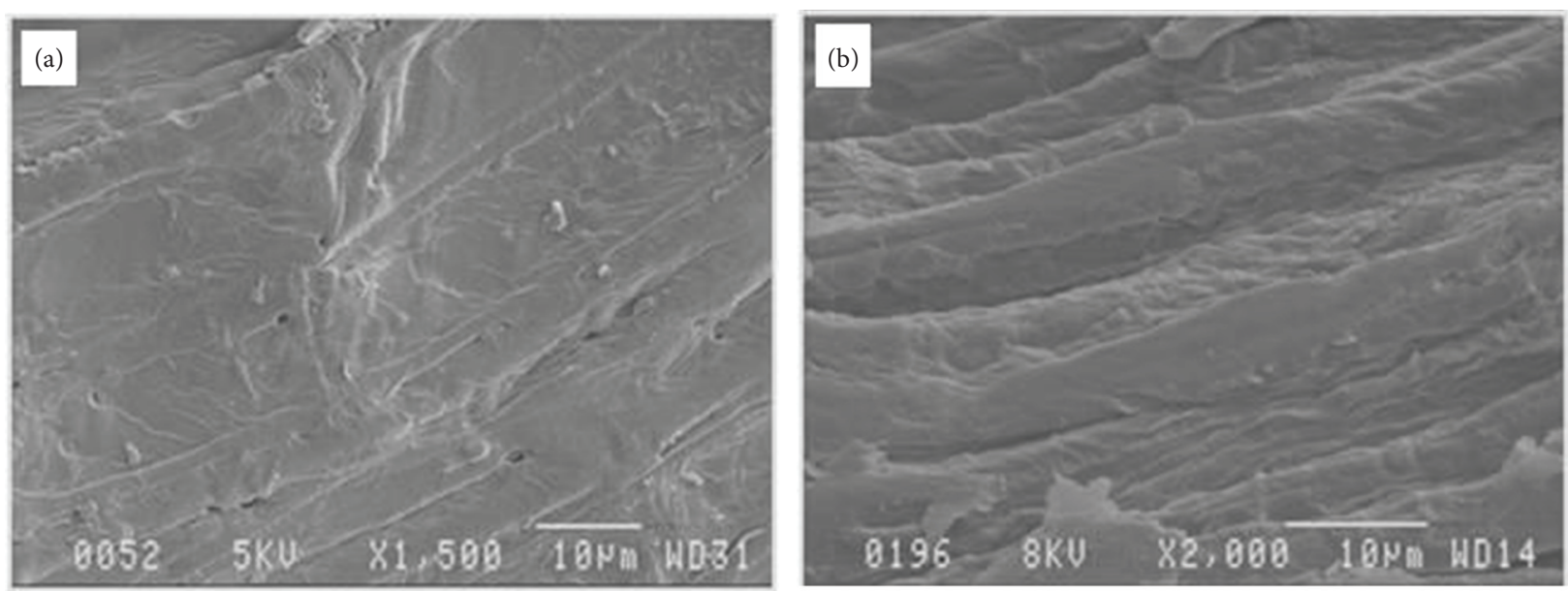

FIGURE 5: SEM images of untreated (a) and alkali-treated (4hr) (b) Borassus fruit fine fibers [28].

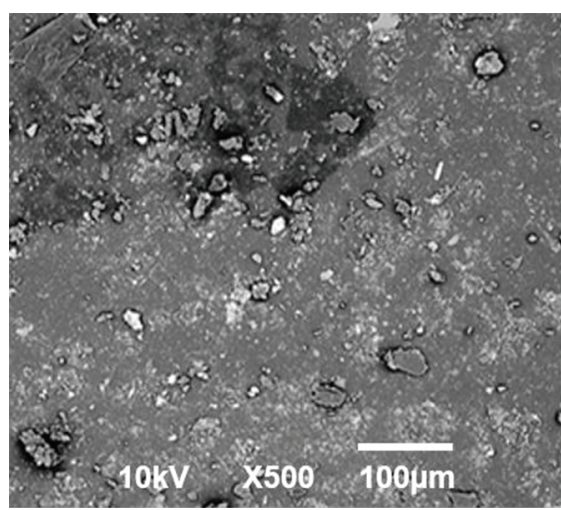

(a)

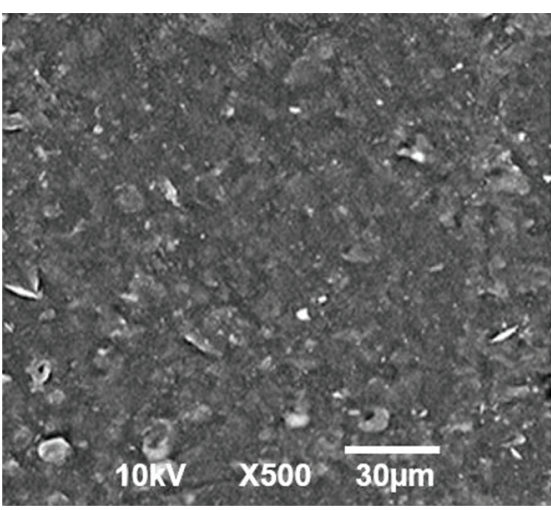

(b)

FIGURE 6: Representative SEM images of (a) untreated BFF fibers/polypropylene polymer composite and (b) alkali-treated BFF fibers/polypropylene polymer composite.

Figures $8(\mathrm{a})-8(\mathrm{~d})$ show the effect of specific wear rate by varying applied loads at a sliding distance of $4000 \mathrm{~m}$. The neat $\mathrm{PP}$ was subjected to lesser wear resistance due to the absence of fibers. A specific wear rate for untreated polypropylene $(\mathrm{U}+\mathrm{PP})$ composites increases firstly and then decreases with an increase in applied load at a particular sliding distance and 


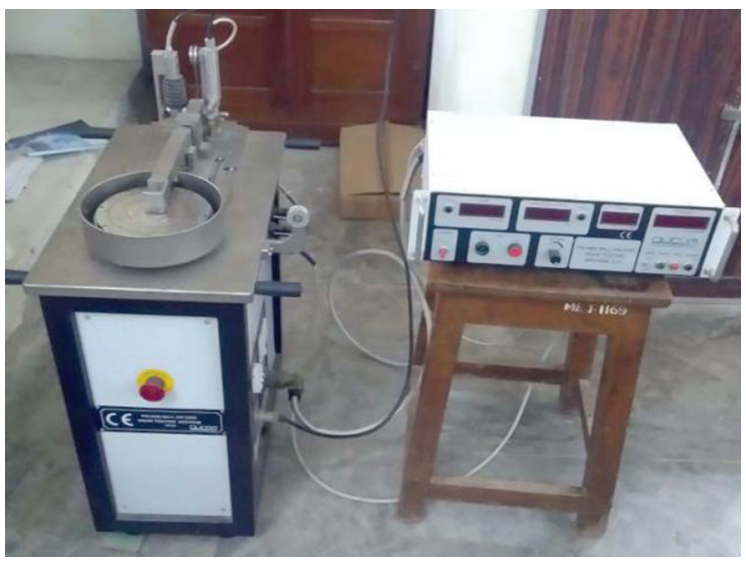

FIgURe 7: Pin-on-disc tribometer setup.

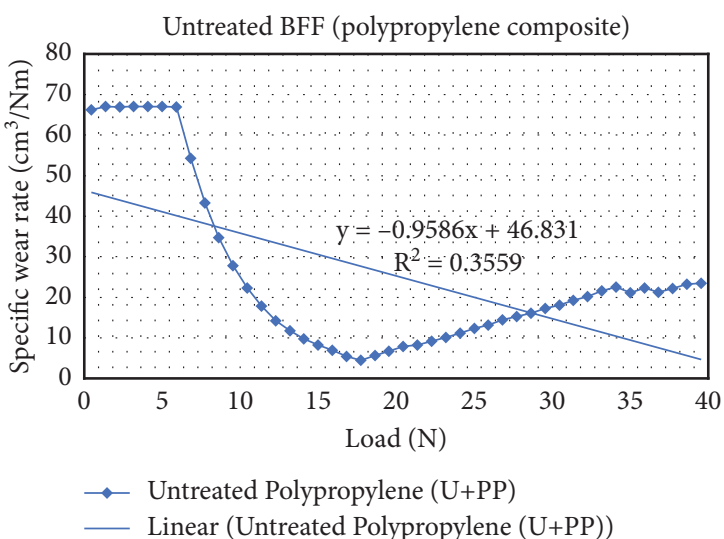

(a)

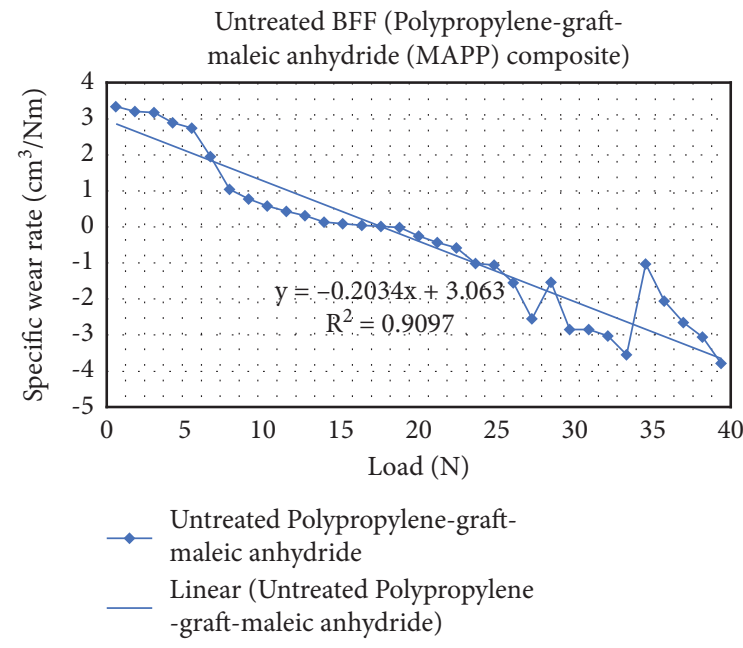

(c)

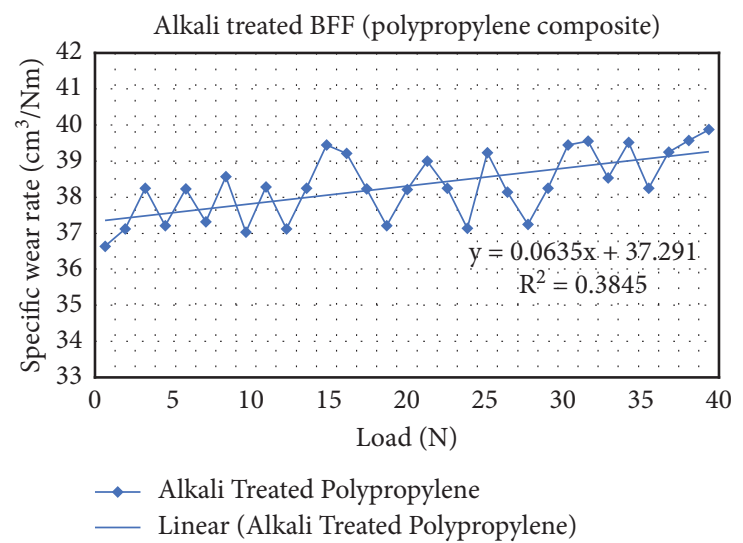

(b)

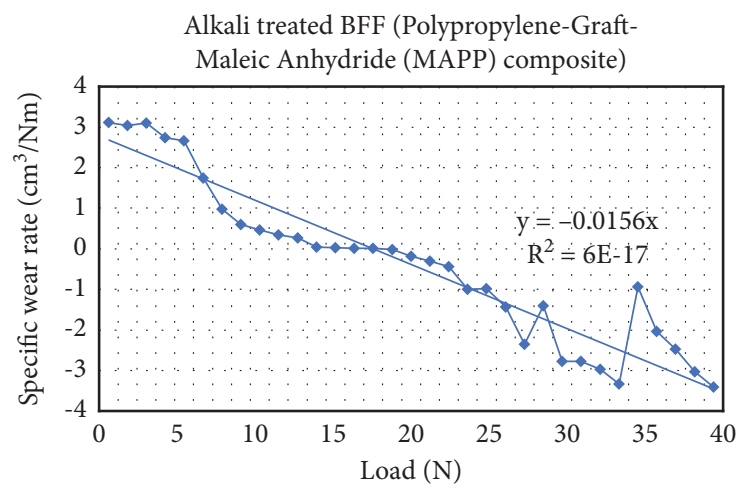

Alkali treated Polypropylene-

Graft-Maleic Anhydride

Linear (Alkali treated Polypropylene

-Graft-Maleic Anhydride)

(d)

Figure 8: (a-d) Specific wear rate versus applied load of specimens at varying load and sliding distance $4000 \mathrm{~m}$.

sliding velocity. The specific wear rate on a volume loss basis reaches a maximum up to $67.01 \mathrm{~cm}^{3} / \mathrm{Nm}$ at an applied load of $9.81 \mathrm{~N}$ and a sliding distance of $4000 \mathrm{~m}$, while specific wear rate for alkali-treated polypropylene $(\mathrm{T}+\mathrm{PP})$ composites also exhibits similar behavior as it firstly increases with applied load and then decreases with increase in applied load at a constant sliding velocity. Specific wear rate on volume loss basis reaches maximum up to $39.87 \mathrm{~cm}^{3} / \mathrm{Nm}$ at an applied load of $19.62 \mathrm{~N}$ and sliding distance of $4000 \mathrm{~m}$, and similarly, specific wear rate for untreated fiber and polypropylene matrix with MAPP compatibilizer (U + PP + MAPP) composites firstly remains constant with applied load and then 


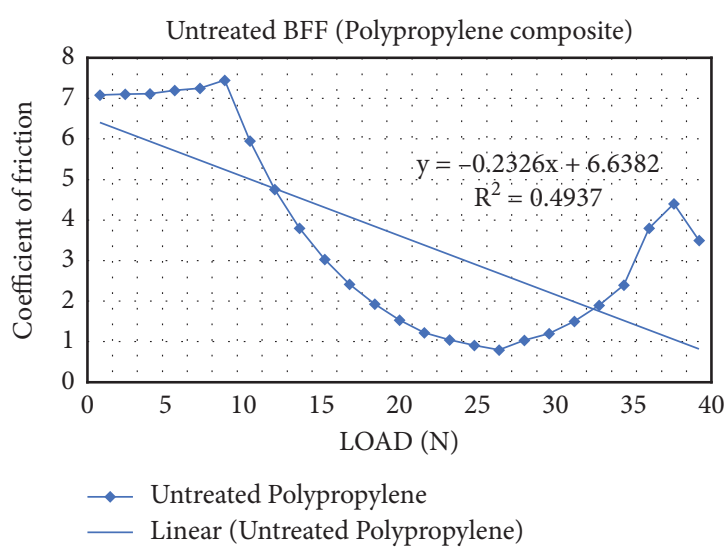

(a)

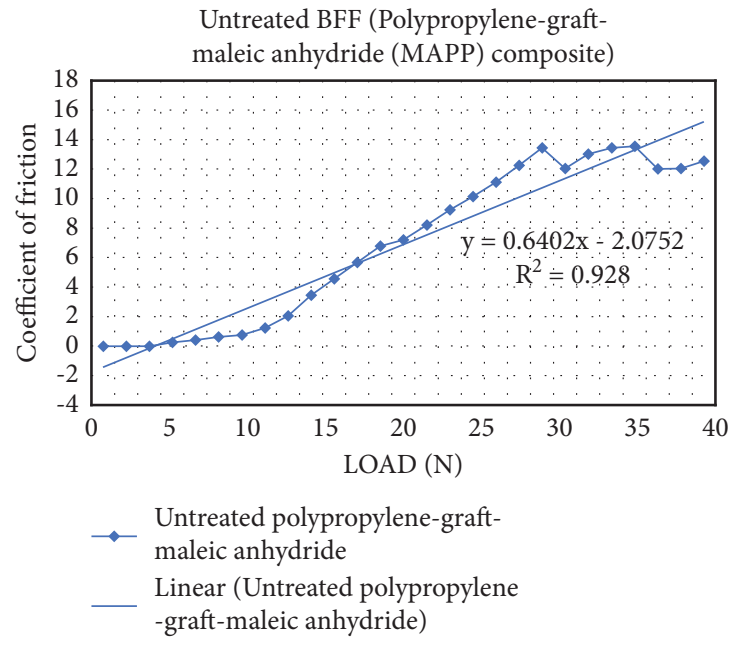

(c)

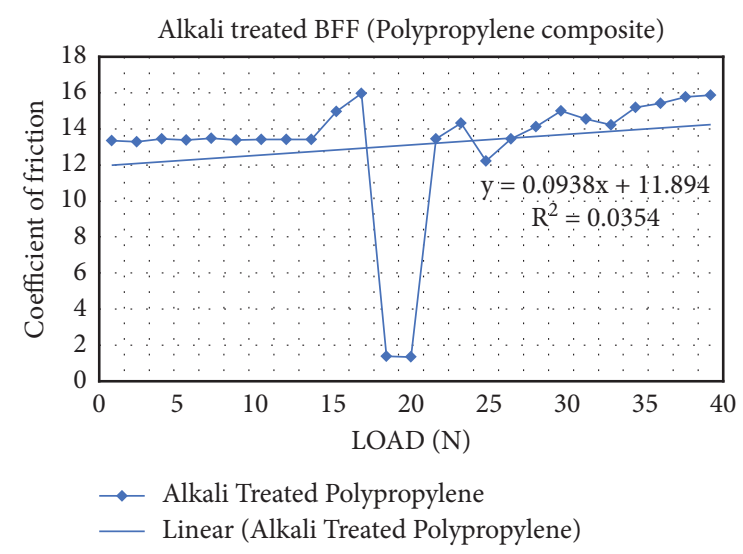

(b)

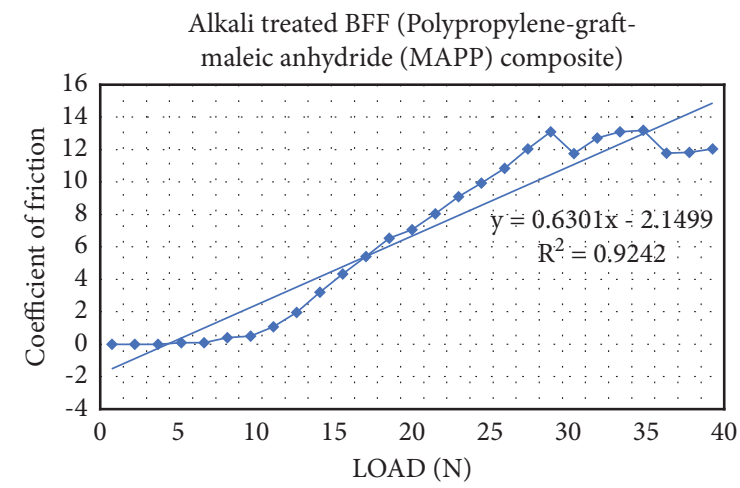

Alkali treated polypropylene-
graft-maleic anhydride
Linear (Alkali treated polypropylene
-graft-maleic Anhydride)

(d)

Figure 9: (a-d) Coefficient of friction versus applied load of specimens at varying load and sliding distance $4000 \mathrm{~m}$.

TABLe 1: Particulars of BFF/PP composite specimens and sliding conditions.

\begin{tabular}{|c|c|c|c|c|c|}
\hline Samples & $\begin{array}{l}\text { \% fiber } \\
\text { weight }\end{array}$ & $\begin{array}{l}\text { Density } \\
\left(\mathrm{g} / \mathrm{cm}^{3}\right)\end{array}$ & $\begin{array}{l}\text { Applied } \\
\text { load }(\mathrm{N})\end{array}$ & $\begin{array}{l}\text { Sliding speed } \\
(\mathrm{m} / \mathrm{sec})\end{array}$ & $\begin{array}{c}\text { Sliding } \\
\text { distance }(\mathrm{m})\end{array}$ \\
\hline Untreated fibers/polypropylene $(\mathrm{U}+\mathrm{PP})$ & 05 & 0.911 & $\begin{array}{c}9.81 \\
19.62 \\
29.43 \\
\end{array}$ & 2.198 & 4000 \\
\hline Alkali-treated fibers/polypropylene (T + PP) & 05 & 0.943 & $\begin{array}{c}9.81 \\
19.62 \\
29.43 \\
\end{array}$ & 2.198 & 4000 \\
\hline Untreated fibers/polypropylene-graft-maleic anhydride (U + PP + MAPP) & 05 & 0.994 & $\begin{array}{c}9.81 \\
19.62 \\
29.43 \\
\end{array}$ & 2.198 & 4000 \\
\hline Alkali-treated fibers/polypropylene-graft-maleic anhydride (T + PP + MAPP) & 05 & 1.041 & $\begin{array}{c}9.81 \\
19.62 \\
29.43\end{array}$ & 2.198 & 4000 \\
\hline
\end{tabular}

decreases with increase in applied load at a constant sliding velocity and sliding distance of $4000 \mathrm{~m}$. Specific wear rate on volume loss basis reaches maximum up to $3.34 \mathrm{~cm}^{3} / \mathrm{Nm}$ at an applied load of $29.43 \mathrm{~N}$ and sliding distance of $4000 \mathrm{~m}$. Specific wear rate for alkali-treated fiber and polypropylene matrix with MAPP compatibilizer ( + PP + MAPP) composites also possesses the same variation as $\mathrm{U}+\mathrm{PP}+\mathrm{MAPP}$, but the wear rate on a volume loss basis reaches a maximum up to $3.11 \mathrm{~cm}^{3} / \mathrm{Nm}$ at an applied load of $29.43 \mathrm{~N}$ and sliding distance of $4000 \mathrm{~m}$. The variation shows the same trendline, 
but due to the presence of MAPP compatibilizer and chemical/surface-modified fibers, the wear rate of $\mathrm{T}+\mathrm{PP}+\mathrm{MAPP}$ possesses better adhesion and good tribological characteristics under dry-sliding conditions. The abrasive wear resistance of T + PP + MAPP composite showed better interfacial adhesion and bonding, thus resulting in better tribological performance as compared to the other three compositions under different loading conditions.

During testing at $29.43 \mathrm{~N}$ load, a change of PP specimen shape has been observed; the contortion and loss of dimensional security may be because of the reprocessed high applied load while sliding. The combined effects of fiber matrix adhesion characteristics, critical fiber length, and mechanical properties of the fiber are the influencing factors reducing wear rates and weight loss of composites.

The mechanical and wear behaviors of naturally woven coconut sheath and glass fiber-reinforced polyester composites have been reported [19]. Based on the results, the factors affecting the mechanical properties and wear behaviors were wt.\% of reinforcement and sliding distance, respectively. When compared with the regular composites, the hybridization again boosted the mechanical abilities of the resulting composites. Worn surfaces were investigated through SEM images for further morphological studies, and the results were reported [19]. The abrasive wear behaviors of lantana camera fiber-reinforced epoxy composites have been presented in a similar manner [20]. The effects of fiber content on the abrasive wear behaviors were evaluated. Based on the test results, the optimum fiber wt.\% was reported as $40 \mathrm{wt} . \%$. Abrasive wear rate was directly proportional to the normal load. The wear mechanisms on the worn surface were investigated through SEM analysis [20]. The investigators also studied and compared the abrasive wear behaviors of polymer composites reinforced with chopped sugarcane fiber, unidirectional sugarcane fiber, and chopped strand mat of glass fiber [21]. The key test parameters considered in the investigation were fiber length, content, orientation, and surface treatment. The effects of the above said parameters on the abrasive wear behaviors were thoroughly investigated and reported. Results showed that the abrasive wear resistance of unidirectional sugarcanereinforced polymer composites was better than the chopped sugarcane-reinforced composites. In case of chopped fiber composites, the random orientation caused the abrasion of fiber in all sides during the abrasion process. The results indicated that the fibers were terribly fractured and sheared in all directions and mass loss increased with respect to sliding distance and time. Due to these facts, the author suggested unidirectional orientation of sugarcane fiber in the polymer matrix in order to have lesser abrasion. The abrasion mechanisms identified in the rubbing surface were seriously connected with the type of reinforcement and orientation. Sugarcane-like soft natural fibers tended to bend effectively under abrasion forces and undergone less fracture and shear when compared to glass fiber-like hard synthetic fibers, which was evident through the SEM observations [21]. The wear and frictional behaviors of sisal fiber-reinforced brake composites have been studied under different contents and friction temperatures [22]. At the end of this study, the optimum proportion of resin and sisal fiber to attain better tribological results was concluded as $3: 4$. By this combination, the friction coefficient was good at a low wave rate for different friction temperatures. Through the results, the authors suggested sisal fiber as a good substitute for asbestos, which is used as brake pads [22].

Figures 9(a)-9(d) show an effect of coefficient of friction by varying applied loads at a sliding distance of $4000 \mathrm{~m}$. Coefficient of friction for untreated polypropylene (U + PP) composites remains constant with applied load and then decreases with a slight increase in applied load at a particular sliding distance and sliding velocity. Coefficient of friction reaches a maximum up to 7.45 at an applied load of $9.81 \mathrm{~N}$ and a sliding distance of $4000 \mathrm{~m}$. Coefficient of friction for alkali-treated polypropylene $(\mathrm{T}+\mathrm{PP})$ composites firstly increases with applied load and then decreases with a slight increase in applied load at a constant sliding velocity. Specific wear rate on volume loss basis reaches maximum up to 15.97 at an applied load of $19.62 \mathrm{~N}$ and sliding distance of $4000 \mathrm{~m}$, and similarly, specific wear rate for untreated fiber and polypropylene matrix with MAPP compatibilizer (U + PP + MAPP) composites firstly remains constant with applied load and then decreases with increase in applied load at a constant sliding velocity and sliding distance of $4000 \mathrm{~m}$. Coefficient of friction on volume loss basis reaches maximum up to 13.55 at an applied load of $29.43 \mathrm{~N}$ and sliding distance of $4000 \mathrm{~m}$. The effective substantial improvement of the coefficient of friction has been observed in alkali-treated fiber and polypropylene matrix with MAPP compatibilizer $(\mathrm{T}+\mathrm{PP}+\mathrm{MAPP})$ composites due to the presence of MAPP compatibilizer and alkali-treated fibers. The frictional coefficient of $\mathrm{T}+\mathrm{PP}+\mathrm{MAPP}$ possesses better interfacial bonding strength upon $\mathrm{NaOH}$ treatment, and coupling agent, which results in enhancement of effective contact surface area and good surface friction characteristics, has been observed under different loading conditions.

It was found from the results that the friction coefficient increased proportionally to the load applied. The coefficients of friction for the untreated fibers were found higher than polymers reinforced with the treated fiber. The treated fiber-reinforced polymer produced less coefficient of friction than others, thus leading to lesser wear. This is because of the strengthened bonding between the treated fibers and the matrix. The interface temperature is also increased due to the change in friction coefficient. The increase in frictional temperature is causing more wear and plastic deformation.

The adhesive wear and frictional performance of bamboo fiber-reinforced epoxy composite has been investigated through pin-on-disc wear testing [23]. The authors tried the three different orientations of reinforcement during composite fabrication and compared the adhesive wear behaviors with respect to all the three orientations. Among all, composite specimens with the antiparallel orientation of fiber possessed superior adhesive wear resistance. Particularly at low sliding velocities, composites with antiparallel oriented fibers showed better adhesive wear performance. The important wear mechanisms that were identified on the worn surface of those composite specimens were grooves and back film transfer [23]. The abrasive wear behavior of 


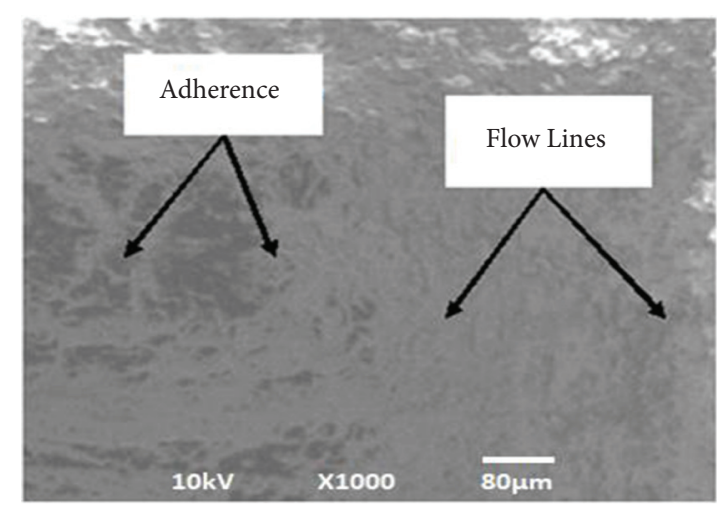

FIgURE 10: SEM micrograph of neat polypropylene (PP) sample at $19.62 \mathrm{~N}$.

jute fiber-reinforced polymer composite has been studied [24]. Maleic anhydride grafted polypropylene was used as a coupling agent to improve the wear resistance. As expected, the wear resistance of the end composite with the coupling agent showed better wear resistance than others. The authors considered the method of coupling agent as inclusion in the composite seriously. In one case, the coupling agent was added during melt mixing, and in another case, the fiber mass was treated with the coupling agent before reinforcing. When comparing the wear behaviors of the end composites obtained from both cases, composites with melt mixing of coupling agent showed better wear resistance than the treated fiber-reinforced composites. The wear mechanisms were studied through the SEM images in order to recognize the abrasive wear performance [24-32]. The coconut sheath-reinforced polyester composite with and without the inclusion of the organomodified MMT nanoclay has been explored [25, 31-37]. The surface chemical treatments of the coconut sheath are carried out by two different manners. One alkali treatment and a silane coupling agent treatment are considered, and the combined effects of fiber surface chemical treatment and MMT nanoclay addition on the tribological properties were evaluated. Four different ranges of nanoclay weight percentage were considered, and the optimum range of the nanoclay weight percentage is concluded as $2 \mathrm{wt} . \%$ based on the effective wear resistance of the resulting composites $[25,38-40]$.

3.2. Analysis of Worn Surface Using FE-SEM. The general wear failure modes in composites are matrix wear, fiber wear, and matrix cracks. The SEM images of the worn surfaces of the neat $\mathrm{PP}$, untreated fiber/PP, untreated fiber/PP with MAPP, and alkali-treated fiber/PP with MAPP compatibilizer samples are shown in Figures 10 to 14, respectively. The worn surfaces showed that the fibers were affected due to peel-off, delamination, and pullout failures.

The thermomechanical loading caused the flow lines and adherences over the worn surface of neat PP as illustrated in Figure 10. The plastic deformation of the matrix leads to the adherence of the same over the surface. Figures 11(a) and 11(b), 12(a) and 12(b), 13, and 14 show the micrographs of BFF fiber-reinforced PP samples. It is clearly visible that some of the raw fibers were debonded from the matrix as revealed in Figure 11(a).

Shear had caused the fibers to debond from the matrix during the wear process. Low adhesion of the untreated fibers resulted in fast fiber debonding. The matrix was separated from the fiber surface at some points, and the large debris was formed as shown in Figure 11(b). Because of debonding, the fibers were pulled out from the matrix. The matrix exposed to the disc was subjected to plastic flow, and debris was formed on the surface. The fractures were also observed on the matrix surface [31-37]. The broken fibers were also noticed on the wear surface as revealed in Figures 11(a) and 11(b).

Figures 12(a) and 12(b) show the micrographs of alkalitreated fiber-reinforced samples. Due to good adhesion, the treated fibers were not normally debonded from the matrix. The samples were worn while wearing. The fibers gave wear resistance at the beginning. Because of this, the coefficient of friction increases and results in mechanical thermo loading. The sliding path and random orientation of the fibers were the factors affecting the values of the coefficient of friction. In the alkali-treated-reinforced BFF fiber composite, crack and fine debris were noticed as revealed in Figure 12(a). The small and large debris were formed on the surface due to matrix wear. Due to the shear force and thermal mismatching between the fiber and matrix, the microcracks were developed on the surface. These microcracks propagated along the sliding direction [35-38]. The partial softening of the matrix formed a thin transfer film on the surface. The pits are formed on the removal of this film during further wear. It is completely obvious that the treated Borassus-fibre reinforcement had shown ploughing traces and strongly recommended the composite materials for low-wear, as shown in Figure 12(b). The softened resin, fine, large debris, and well-bonded fibers in the SEM image ensured the same. For the untreated fiber-reinforced composite with MAPP and alkali-treated fiber-reinforced composite with MAPP, it was noticed that the fibers were less debonded towards the sliding direction, and on the other side, the good interfacial adhesion was observed as 


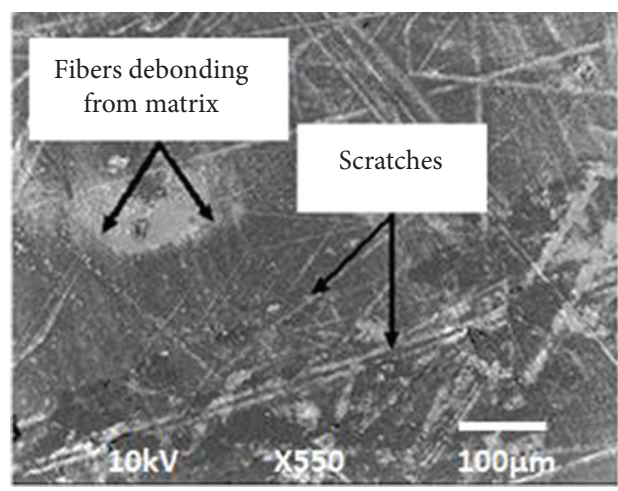

(a)

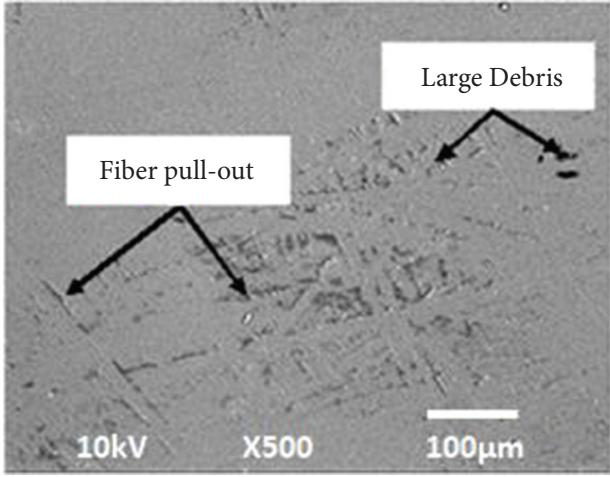

(b)

FIGURE 11: (a) SEM Micrograph of worn untreated polypropylene (U + PP) sample at $9.81 \mathrm{~N}$ and (b) SEM micrograph of worn untreated polypropylene $(\mathrm{U}+\mathrm{PP})$ sample at $19.62 \mathrm{~N}$.

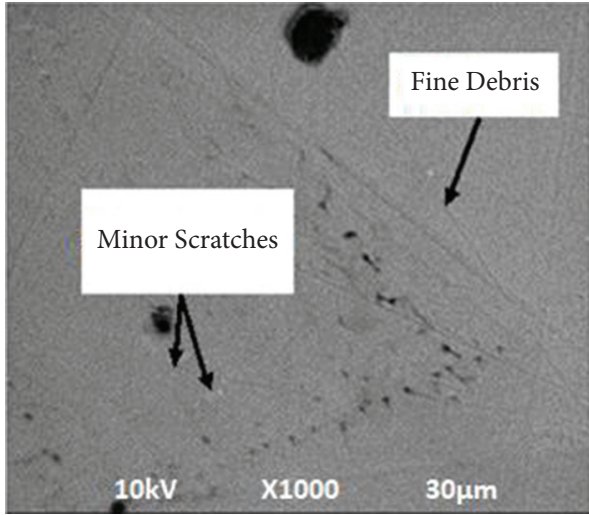

(a)

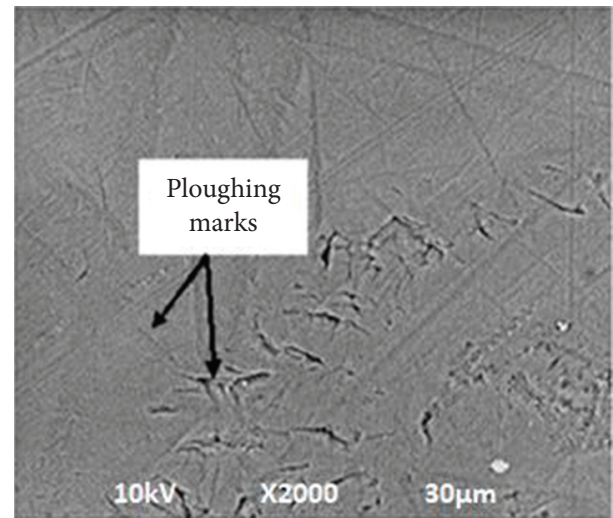

(b)

FIGURE 12: (a) SEM micrograph of worn alkali-treated polypropylene $(\mathrm{T}+\mathrm{PP})$ sample at $9.81 \mathrm{~N}$ and (b) SEM micrograph of worn alkalitreated polypropylene $(\mathrm{T}+\mathrm{PP})$ sample at $19.62 \mathrm{~N}$.

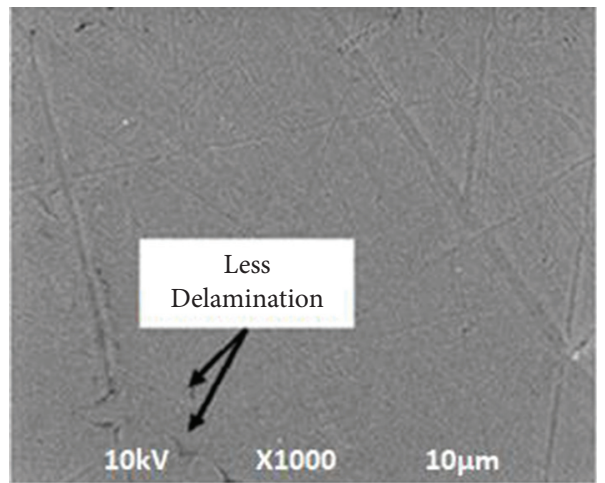

FIGURE 13: SEM micrograph of worn untreated polypropylene-graft-maleic anhydride $(\mathrm{U}+\mathrm{PP}+\mathrm{MAPP})$ sample at different loading conditions.

revealed in Figure 13 and 14, respectively. The softened PP matrix over the surface was observed in both the above cases. Some of the fibers were peeled off during the wear process [38-55]. The fabricated novel composites can be worthwhile for numerous engineering applications as shown in Figure 15. 


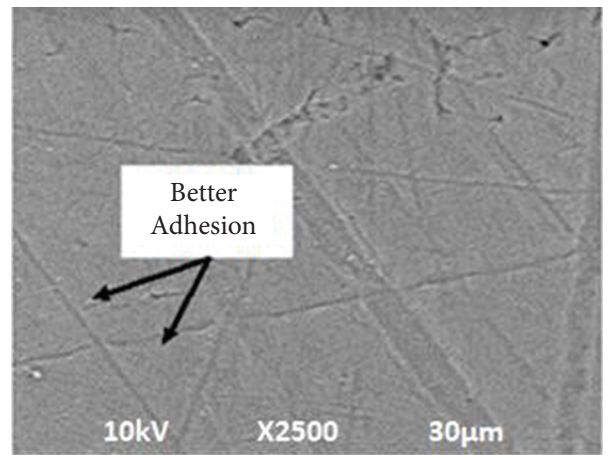

FIGURE 14: SEM micrograph of worn alkali-treated polypropylene-graft-maleic anhydride ( $+\mathrm{PP}+\mathrm{MAPP})$ sample at different loading conditions.
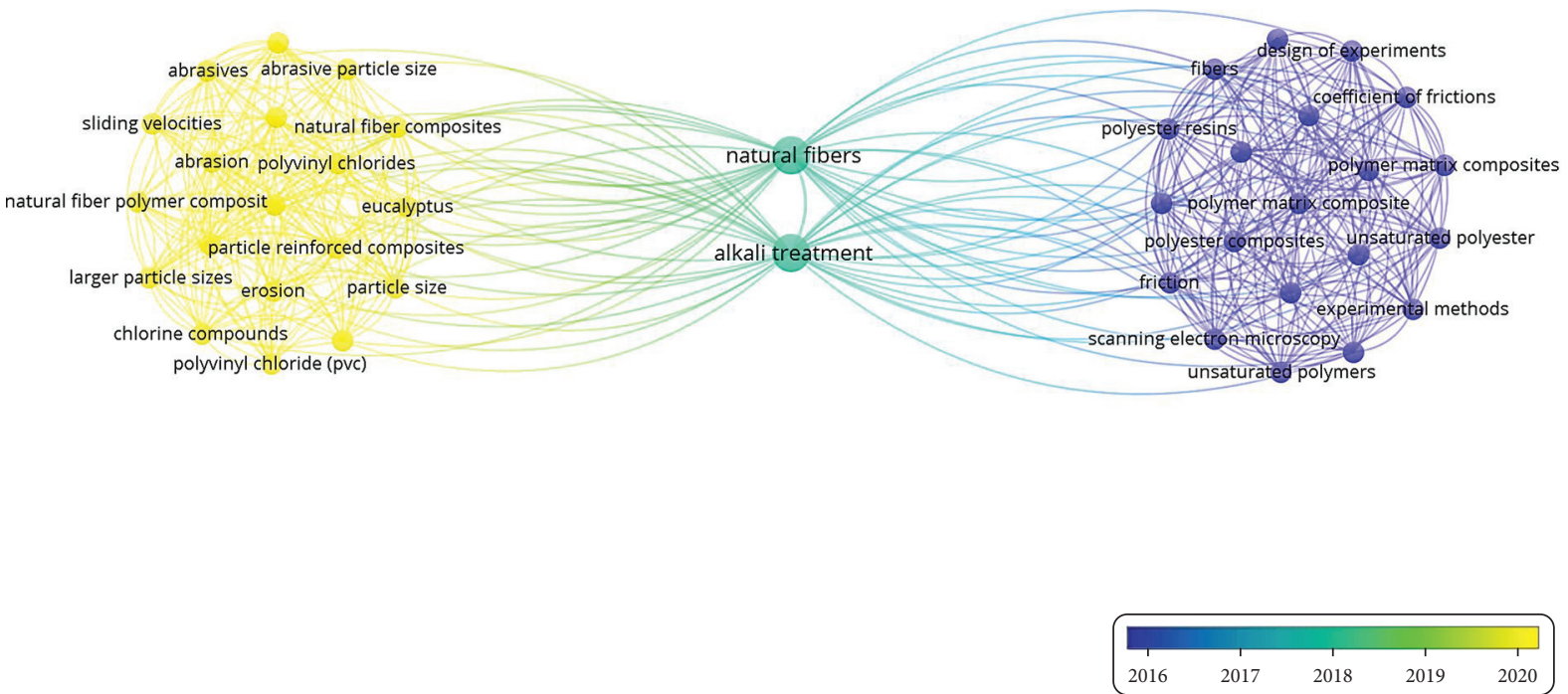

FIGURE 15: Systematic mapping summary of scientific advancements regarding the influence of alkali treatment and MAPP compatibilizing agent on physicomechanical and sliding wear tribological characteristics of natural fiber-reinforced polymer composites for engineering applications.

\section{Conclusions}

The wear properties of chopped Borassus fruit fiber-reinforced PP composites were analyzed, and the following conclusions were reached:

(i) The incorporation of Borassus fruit fibers in the PP matrix significantly reduced the friction coefficient and the adhesive wear weight loss of the neat PP matrix. The reinforcement of Borassus fruit fibers also enhanced neat PP wear resistance.

(ii) The alkali-treated fiber reinforcement demonstrated superior wear properties to the composites than the untreated reinforcement. Because of the alkali processing, removal of surface impurities from the fiber favored improved adhesion of the fiber matrix and thus wear properties.

(iii) Wear properties are determined by the length of the fiber. Alkali-treated $\mathrm{PP} / \mathrm{BFF}$ fiber reinforcement preferred better wear properties when slipping against stainless steel from the untreated fiber/PP, alkali-treated fiber/PP, untreated fiber/PP with MAPP, and alkali-treated fiber/PP with MAPP.

(iv) The BFF fibers were short in length. Hence, detachment and fiber pullouts during wear were the reason for their low performance. The BFF fibers were entangled in the matrix and showed better wear properties than the short fiber reinforcement and lesser wear properties than the $5 \%$ wt. reinforcement for BFF/PP with MAPP. The fibers were well embedded with matrix and indicated that it is close to critical fiber length at which the wear rate was minimum.

(v) The wear behavior changed according to the various speeds. When the velocity is increased at higher speeds, the corresponding weight loss and the wear rate are found to be increased.

(vi) The various failure modes due to wear were studied by SEM. Better fiber matrix adhesion and bonding were observed for the treated fiber-reinforced specimens. The wear failure mechanisms like 
pitting, peel-off, cracks, and delamination proved the same. Better interfacial bonding was observed for the alkali-treated BFF fiber-reinforced PP with MAPP composites.

(vii) The naturally available Borassus fruit fibers can replace the synthetic fibers due to their improved wear properties. Based on the experimentation, this paper suggests the use of alkali-treated Borassus fruit fibers with MAPP to cater to tribological applications.

\section{Data Availability}

No data were used to support this study.

\section{Conflicts of Interest}

The authors declare that they have no conflicts of interest.

\section{Acknowledgments}

The authors Shubham Sharma and Sumit Nijjar wish to acknowledge the Department of RIC, IKGPTU, Kapurthala, for providing the opportunity to conduct this research task. The author P. Sudhakara gratefully acknowledges the financial support from Science and Engineering Research Board (SERB) (Ref. no. YSS/2015/001294), New Delhi, India, and is also thankful to CATERS, CSIR-CLRI, for providing SEM analysis for this study. The authors would also like to sincerely acknowledge the valuable contributions of CSIRCLRI with CSIR-CLRI communication no. 1637 for utilizing the research resources in order to carry out this work.

\section{References}

[1] H. Ku, H. Wang, N. Pattarachaiyakoop, and M. Trada, "A review on the tensile properties of natural fiber reinforced polymer composites," Composites Part B: Engineering, vol. 42, no. 4, pp. 856-873, 2011.

[2] L. Liu, Z. Wang, Y. Yu et al., "Engineering interfaces toward high-performance polypropylene/coir fiber biocomposites with enhanced friction and wear behavior," ACS Sustainable Chemistry \& Engineering, vol. 7, no. 22, pp. 18453-18462, 2019.

[3] S. A. R. Hashmi, U. K. Dwivedi, and N. Chand, "Graphite modified cotton fibre reinforced polyester composites under sliding wear conditions," Wear, vol. 262, no. 11-12, pp. 1426-1432, 2007.

[4] B. F. Yousif and N. S. M. El-Tayeb, "Wet adhesive wear characteristics of untreated oil palm fibre-reinforced polyester and treated oil palm fibre-reinforced polyester composites using the pin-on-disc and block-on-ring techniques," Proceedings of the Institution of Mechanical Engineers - Part J: Journal of Engineering Tribology, vol. 224, no. 2, pp. 123-131, 2009.

[5] B. Yousif, O. Leong, L. Ong, and W. Jye, "The effect of treatment on tribo-performance of CFRP composites," Recent Patents on Materials Science, vol. 2, no. 1, pp. 67-74, 2009.

[6] U. Nirmal, "Prediction of friction coefficient of treated betelnut fibre reinforced polyester (T-BFRP) composite using artificial neural networks," Tribology International, vol. 43, no. 8, pp. 1417-1429, 2010.
[7] S. Narish, B. F. Yousif, and R. Dirk, "Tribological characteristics of sustainable fiber-reinforced thermoplastic composites under wet adhesive wear," Tribology Transactions, vol. 54, pp. 736-748, 2011.

[8] P. K. Bajpai, I. Singh, and J. Madaan, "Tribological behavior of natural fiber reinforced PLA composites," Wear, vol. 297, no. 1-2, pp. 829-840, 2013.

[9] A. Shalwan and B. F. Yousif, "Influence of date palm fibre and graphite filler on mechanical and wear characteristics of epoxy composites," Materials \& Design, vol. 59, pp. 264-273, 2014.

[10] R. A. Ibrahem, "Friction and wear behaviour of fibre/particles reinforced polyester composites," International Journal of Applied Mathematical Research, vol. 2, no. 2, pp. 22-26, 2016.

[11] U. K. Dwivedi and N. Chand, "Influence of wood flour loading on tribological behavior of epoxy composites," Polymer Composites, pp. 1-4, 2008.

[12] N. S. M. El-Tayeb, "A study on the potential of sugarcane fibers/polyester composite for tribological applications," Wear, vol. 265, no. 1-2, pp. 223-235, 2008.

[13] W. Brostow, K. Vera, D. Vrsaljko, and J. Whitworth, "Tribology of polymers and polymer-based Composites," Journal of Materials Education, vol. 32, no. 5-6, pp. 273-290, 2010.

[14] M. Punyapriya and S. K. Acharya, "Anisotropy abrasive wear behavior of bagasse fiber reinforced polymer composite," International Journal of Engineering, Science and Technology, vol. 2, no. 11, pp. 104-112, 2010.

[15] B. Aldousiri, A. Shalwan, and C. W. Chin, "A review on tribological behaviour of polymeric composites and future reinforcements," Advances in Materials Science and Engineering, vol. 2013, pp. 1-8, 2013.

[16] K. B. Kamal, M. Niharika, and S. K. Acharya, "Effect of fiber loading on abrasive wear behavior of Ipomoea carnea reinforced epoxy composite," International Journal of Plastic Technology, vol. 18, no. 1, pp. 64-74, 2014.

[17] Y. Sahin, "Analysis of abrasive wear behavior of PTFE composite using Taguchi's technique," Cogent Engineering, vol. 2, no. 1000510, pp. 1-15, 2015.

[18] N. Aranganathan, V. Mahale, and J. Bijwe, "Effects of aramid fiber concentration on the friction and wear characteristics of non-asbestos organic friction composites using standardized braking tests," Wear, vol. 354-355, pp. 69-77, 2016.

[19] I. Siva, J. T. W. Jappes, and B. Suresha, "Investigation on mechanical and tribological behavior of naturally woven coconut sheath-reinforced polymer composites," Polymer Composites, vol. 33, no. 5, pp. 723-732, 2012.

[20] C. Deo and S. K. Acharya, "Effect of fiber content on abrasive wear of lantana camara fiber reinforced polymer matrix composite," Indian journal of engineering \& material science, vol. 17, no. 1, pp. 219-223, 2010.

[21] El-Tayeb and NSM 2009, "Two body abrasive behaviour of untreated SC and R-G fibres polyester composites," Wear, vol. 266, no. 1, pp. 220-232, 2009.

[22] X. Xu, G. X. Cheng, and F. Q. Liu, "Friction properties of sisal fibre reinforced resin brake composites," Wear, vol. 262, no. 1, pp. 736-741, 2007.

[23] U. Nirmal, J. Hashim, and K. O. Low, "Adhesive wear and frictional performance of bamboo fibres reinforced epoxy composite," Tribology International, vol. 47, no. 1, pp. 22-133, 2012.

[24] N. Chand and U. K. Dwivedi, "Effect of coupling agent on abrasive wear behaviour of chopped jute fibre-reinforced polypropylene composites," Wear, vol. 261, no. 10, pp. 1057-1063, 2006. 
[25] N. Rajini, J. W. Jappes, B. Suresha, S. Rajakarunakaran, I. Siva, and N. Azhagesan, "Effect of organically modified montmorillonite clay on wear behavior of naturally woven coconut sheath/polyester composite," Proceedings of the Institution of Mechanical Engineers - Part J: Journal of Engineering Tribology, vol. 228, no. 5, pp. 483-497, 2014.

[26] T. Lu, M. Jiang, Z. Jiang, D. Hui, Z. Wang, and Z. Zhou, "Effect of surface modification of bamboo cellulose fibers on mechanical properties of cellulose/epoxy composites," Composites Part B: Engineering, vol. 51, pp. 28-34, 2013.

[27] M. M. Kabir, H. Wang, K. T. Lau, and F. Cardona, "Chemical treatments on plant-based natural fibre reinforced polymer composites: an overview," Composites Part B: Engineering, vol. 43, no. 7, pp. 2883-2892, 2012.

[28] P. Sudhakara, D. Jagadeesh, Y. Wang et al., "Fabrication of Borassus fruit lignocellulose fiber/PP composites and comparison with jute, sisal and coir fibers," Carbohydrate Polymers, vol. 98, no. 1, pp. 1002-1010, 2013.

[29] P. Sudhakara, K. Obi Reddy, C. V. Prasad et al., "Studies on Borassus fruit fiber and its composites with Polypropylene," Composites Research, vol. 26, no. 1, pp. 48-53, 2013.

[30] B. Vinod, S. Suresh, and D. Sudhakara, "Investigation of biodegradable hybrid composites: effect of fibers on tribomechanical characteristics," Advanced Composites and Hybrid Materials, vol. 3, no. 2, pp. 194-204, 2020.

[31] C. Liu, Q. Yin, X. Li et al., “A waterborne polyurethane-based leather finishing agent with excellent room temperature selfhealing properties and wear-resistance," Advanced Composites and Hybrid Materials, vol. 4, no. 1, pp. 138-149, 2021.

[32] B. V. Lingesh, B. N. Ravi Kumar, B. M. Rudresh, and H. N. Reddappa, "Hybridization effect of fibers on mechanical properties of PA66/PP blend-based thermoplastic composites," Advanced Composites and Hybrid Materials, vol. 1, no. 4, pp. 766-776, 2018.

[33] J. Ma, Z. J. Li, Y. Z. B. Xue, X. Y. Liang, Z. J. Tan, and B. Tang, "Novel PEEK/nHA composites fabricated by hot-pressing of 3D braided PEEK matrix," Advanced Composites and Hybrid Materials, vol. 3, no. 2, pp. 156-166, 2020.

[34] G. Guo, V. L. Finkenstadt, and Y. Nimmagadda, "Mechanical properties and water absorption behavior of injection-molded wood fiber/carbon fiber high-density polyethylene hybrid composites," Advanced Composites and Hybrid Materials, vol. 2, no. 4, pp. 690-700, 2019.

[35] A. Balaji, B. Karthikeyan, and J. Suminathan, "Comparative mechanical, thermal, and morphological study of untreated and $\mathrm{NaOH}$-treated bagasse fiber-reinforced cardanol green composites," Adv Compos Hybrid Mater, vol. 2, pp. 125-132, 2019.

[36] R. Gopinath, R. Poopathi, and S. S. Saravanakumar, "Characterization and structural performance of hybrid fiberreinforced composite deck panels," Advanced Composites and Hybrid Materials, vol. 2, no. 1, pp. 115-124, 2019.

[37] Y. Xu, J. Zhu, Z. Wu, Y. Cao, Y. Zhao, and W. Zhang, "A review on the design of laminated composite structures: constant and variable stiffness design and topology optimization," Advanced Composites and Hybrid Materials, vol. 1, no. 3, pp. 460-477, 2018.

[38] H. Yang, B. C. Ng, H. C. Yu, H. H. Liang, C. Kwok, and W. Lai, "Mechanical properties study on sandwich hybrid metal/ (carbon, glass) fiber reinforcement plastic composite sheet," Advanced Composites Hybrid Materials, vol. 3, 2021.

[39] S. Yang, Y. Liu, Z. Jiang, J. Gu, and D. Zhang, "Thermal and mechanical performance of electrospun chitosan/poly(vinyl alcohol) nanofibers with graphene oxide," Advanced Composites and Hybrid Materials, vol. 1, no. 4, pp. 722-730, 2018.

[40] R. B. Ashok, C. V. Srinivasa, and B. Basavaraju, "Dynamic mechanical properties of natural fiber composites-a review," Advanced Composites and Hybrid Materials, vol. 2, no. 4, pp. 586-607, 2019.

[41] J. S. Chohan, N. Mittal, R. Kumar et al., "Optimization of FFF process parameters by naked mole-rat algorithms with enhanced exploration and exploitation capabilities," Polymers, vol. 13, no. 11, p. 1702, 2021.

[42] R. A. Ilyas, S. M. Sapuan, M. R. M. Asyraf et al., "Polymer composites filled with metal derivatives: a review of flame retardants," Polymers, vol. 13, no. 11, p. 1701, 2021.

[43] J. S. Chohan, N. Mittal, R. Kumar et al., "Mechanical strength enhancement of 3D printed acrylonitrile butadiene styrene polymer components using neural network optimization algorithm," Polymers, vol. 12, no. 10, p. 2250, 2020.

[44] Y. Singh, J. Singh, S. Sharma, V. Aggarwal, and C. I. Pruncu, "Multi-objective optimization of kerf-taper and surfaceroughness quality characteristics for cutting-operation on coir and carbon fibre reinforced epoxy hybrid polymeric composites during CO2-pulsed laser-cutting using RSM," Lasers in Manufacturing and Materials Processing, vol. 8, no. 2, pp. 157-182, 2021.

[45] S. Sharma, J. Singh, H. Kumar et al., "Utilization of rapid prototyping technology for the fabrication of an orthopedic shoe inserts for foot pain reprieve using thermo-softening viscoelastic polymers: a novel experimental approach," Measurement and Control, vol. 53, no. 3-4, pp. 519-530, 2020.

[46] Y. Singh, J. Singh, S. Sharma, A. Sharma, and J. S. Chohan, "Process parameter optimization in laser cutting of coir fiber reinforced epoxy composite-a review," Mater. Today Proc., pp. 4738-4744. in press, 2021.

[47] J. S. Chohan, R. Kumar, T. B. Singh et al., "Taguchi S/N and TOPSIS based optimization of fused deposition modelling and vapor finishing process for manufacturing of ABS plastic parts," Materials, vol. 13, no. 22, p. 5176, 2020.

[48] S. Prabhakaran, V. Krishnaraj, S. Sharma, M. Senthilkumar, R. Jegathishkumar, and R. Zitoune, "Experimental study on thermal and morphological analyses of green composite sandwich made of flax and agglomerated cork," Journal of Thermal Analysis and Calorimetry, vol. 139, no. 5, pp. 30033012, 2020.

[49] S. Sharma, P. Sudhakara, J. Singh, R. A. Ilyas, M. R. M. Asyraf, and M. R. Razman, "Critical review of biodegradable and bioactive polymer composites for bone tissue engineering and drug delivery applications," Polymers, vol. 13, no. 16, p. 2623, 2021.

[50] S. Sharma, P. Sudhakara, A. A. B. Omran, J. Singh, and R. A. Ilyas, "Recent trends and developments in conducting polymer nanocomposites for multifunctional applications," Polymers, vol. 13, no. 17, p. 2898, 2021.

[51] K. Jha, Y. K. Tyagi, R. Kumar et al., “Assessment of dimensional stability, biodegradability, and fracture energy of biocomposites reinforced with novel pine cone," Polymers, vol. 13 , no. 19, p. 3260, 2021.

[52] A. Kadier, R. A. Ilyas, M. R. M. Huzaifah et al., "Use of industrial wastes as sustainable nutrient sources for bacterial cellulose (BC) production: mechanism, advances, and future perspectives," Polymers, vol. 13, no. 19, p. 3365, 2021.

[53] Y. Singh, J. Singh, S. Sharma, T.-D. Lam, and D.-N. Nguyen, "Fabrication and characterization of coir/carbon-fiber reinforced epoxy based hybrid composite for helmet shells and sports-good applications: influence of fiber surface modifications on the mechanical, thermal and morphological 
properties," Journal of Materials Research and Technology, vol. 9, no. 6, pp. 15593-15603, 2020.

[54] M. J. Suriani, R. A. Ilyas, M. Y. M. Zuhri et al., "Critical review of natural fiber reinforced hybrid composites: processing, properties, applications and cost," Polymers, vol. 13, no. 20, p. 3514, 2021.

[55] R. Kumar, N. Ranjan, V. Kumar et al., "Characterization of friction stir-welded polylactic acid/aluminum composite primed through fused filament fabrication," Journal of Materials Engineering and Performance, 2021. 